\title{
Dry particle generation with a 3-D printed fluidized bed generator
}

\author{
Michael Roesch $^{1}$, Carolin Roesch ${ }^{1}$, and Daniel J. Cziczo ${ }^{1,2}$ \\ ${ }^{1}$ Department of Earth, Atmospheric and Planetary Sciences, Massachusetts Institute of Technology, Cambridge, 02139, USA \\ ${ }^{2}$ Department of Civil Environmental Engineering, Massachusetts Institute of Technology, Cambridge, 02139, USA
}

Correspondence to: Michael Roesch (roesch@mit.edu)

Received: 2 December 2016 - Discussion started: 17 January 2017

Revised: 28 April 2017 - Accepted: 2 May 2017 - Published: 2 June 2017

\begin{abstract}
Here we describe the design and testing of PRIZE (PRinted fluidIZed bed gEnerator), a compact fluidized bed aerosol generator manufactured using stereolithography (SLA) printing. Dispersing small quantities of powdered materials - due to either rarity or expense - is challenging due to a lack of small, low-cost dry aerosol generators. With this as motivation, we designed and built a generator that uses a mineral dust or other dry powder sample mixed with bronze beads that sit atop a porous screen. A particle-free airflow is introduced, dispersing the sample as airborne particles. Total particle number concentrations and size distributions were measured during different stages of the assembling process to show that the SLA 3-D printed generator did not generate particles until the mineral dust sample was introduced. Time-series measurements with Arizona Test Dust (ATD) showed stable total particle number concentrations of 10$150 \mathrm{~cm}^{-3}$, depending on the sample mass, from the sub- to super-micrometer size range. Additional tests with collected soil dust samples are also presented. PRIZE is simple to assemble, easy to clean, inexpensive and deployable for laboratory and field studies that require dry particle generation.
\end{abstract}

\section{Introduction}

Investigating dry powder samples, such as mineral and soil dust and volcanic ash, is essential to understand their atmospheric influence, especially on clouds (Boucher et al., 2013). Inexpensive commercial nebulizers have often been used to aerosolize these types of samples but require them first to be made into a water slurry. Sullivan et al. (2010), Kumar et al. (2011), Garimella et al. (2014) and Tang et al. (2016) demonstrated that such aqueous processing alters the surface composition, physiochemical properties and hygroscopicity of the particles even after condensed-phase water is completely removed. Samples therefore often need to be dispersed by particle generators that do not change these characteristics. Different types of generators, such as rotating brush generators (Cziczo et al., 2013; Hiranuma et al., 2015), fluidized bed generators (FBGs) (Tobo et al., 2012; Hartmann et al., 2016) and shakers (Garimella et al., 2014), have been used for dry dispersion depending on the amount of material and the experimental setup. In some applications only a small number of particles is needed, or for a short period of time. These include some filter sampling (Ardon-Dryer and Levin, 2014), electrodynamic and other particle trapping (Hesse et al., 2002) and single particle mass spectrometry (Murphy, 2006). Moreover, the sample to be aerosolized might be limited due to rarity or expense, necessitating a generation system capable of working with gram-level quantities. These uses motivate a small, low-cost and easy-to-set-up dry particle generator.

FBGs have been used in several studies to disperse dry samples as sub- to super-micrometer size range aerosol particles (Guichard, 1976; Moreno and Blann, 1976; Boucher and Lua, 1982; Wang et al., 1998; Gauthier et al., 1999; Niedermeier et al., 2010; Clemente et al., 2013) with commercially available version such as the TSI Fluidized Bed Aerosol Generator (FBAG, model 3400A, TSI Inc.) or the small-scale powder disperser (SSPD, model 3343, TSI Inc.). Some issues with dispersion have become apparent from the use of these instruments. Sub-10 $\mu \mathrm{m}$ diameter particles are difficult to disperse due to cohesive forces (Geldart, 1973); the dispersibility of a dust sample increases with increasing particle size (Hinds, 1999). While a broad size range of the material being dispersed typically enables better aerosolization, it may also lead to particle segregation in the bed (Lind et al., 2010). Another issue faced by FBGs is that the material to be 
(a)

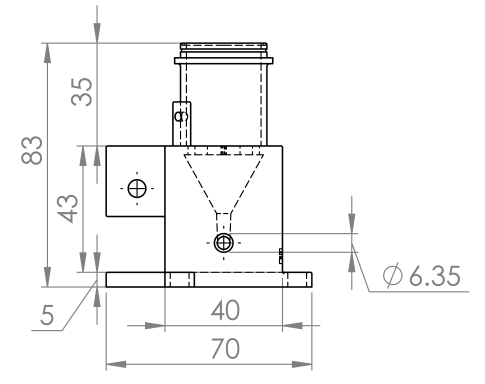

(c)

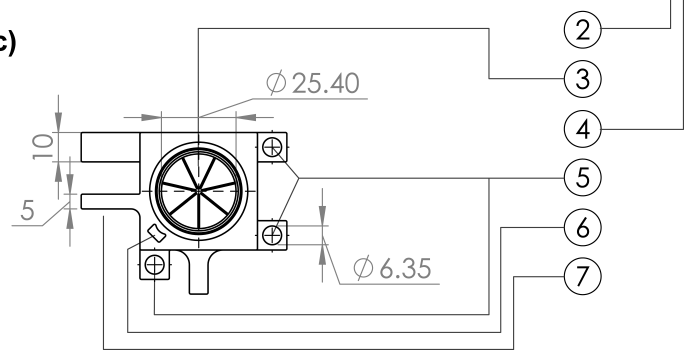

Figure 1. Dimensioned drawings of PRIZE: (a) rear view; (b) side view; (c) top view. All dimensions are in millimeters. The generator body consists of seven components: (1) inlet, (2) internal cone, (3) radial grid with openings, (4) elutriator tube, (5) mounting holes, (6) LED mount and (7) rotameter (or other flow meter) mount.

dispersed is often charged due to triboelectrification. This is caused by friction between the generator walls, the beads and the particles themselves (Mehrani et al., 2007). Using conductive wall material or ionization through radioactive neutralizers can decrease this effect (Boucher and Lua, 1982; Forsyth et al., 1998). An alternative means of particle production is agitation of dry materials (Sullivan et al., 2009). Examples include flasks in combination with ultrasonic baths or mechanical shakers. In both cases, mechanical or other agitation devices need to be combined with sample containers and flow hardware for aerosolization of samples.

The objective of this study was to produce a small, lowcost 3-D printed FBGs able to disperse small quantities of dry micrometer-sized samples without artifact particles from either the generator or bed. In comparison to existing dispersion devices, the PRIZE (PRinted fluidIZed bed gEnerator) does not contain moving parts, features smaller dimensions and mass and has a lower cost, requiring only access to 3D printing. This allows for multiple PRIZEs to be used with different samples, thereby reducing the time and possible artifacts associated with cleaning procedures on a single generator. (a)

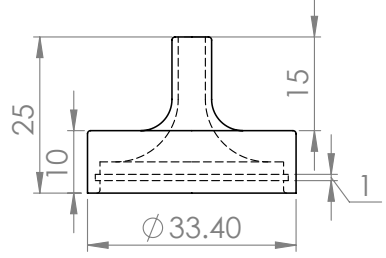

(b)

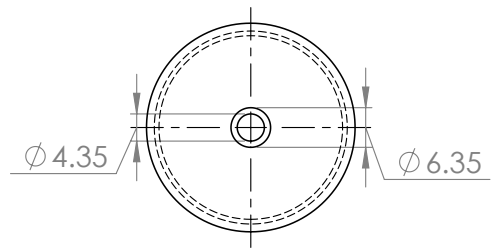

Figure 2. Dimensioned drawing of a single port outlet lid: (a) side view; (b) top view. All dimensions are in millimeters.

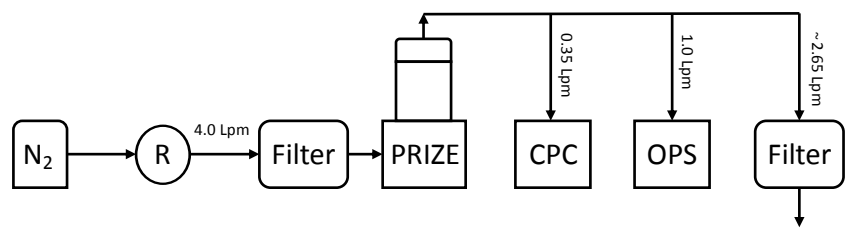

Figure 3. Schematic of the experimental setup used in this study. A filtered dry nitrogen flow was controlled by a rotameter $(\mathrm{R})$ upstream of PRIZE. Downstream, the flow was split into three parts to a CPC, an OPS and excess flow discarded through a filter.

\section{Methods}

\subsection{Design}

PRIZE consists of two main parts, the generator body (Fig. 1) and exchangeable lids with customizable outlet configurations (Fig. 2). The instrument, except the porous screen and the bronze beads comprising the bed, was designed using a computer-aided design (CAD) program (Solidworks 2015; Dassault Systems). The PRIZE follows similar designs by Marple et al. (1978). In contrast to the aforementioned generator or the commercially available FBAG and SSPD, PRIZE does not contain any moving parts or a supply chain to feed fresh dry powder into the bed. This feature was chosen to keep the setup simple and reproducible.

At the bottom of the generator there is a $6.35 \mathrm{~mm}(0.25 \mathrm{in}$.) tube inlet to introduce the particle-free carrier gas. The inlet was designed to fit common tube connectors. Downstream of the inlet, an internal cone with seven radially equidistant arms supports a $25.4 \mathrm{~mm}$ diameter porous screen. This screen supports the bed and sample while also allowing a homogeneous flow pattern through the bed. The porous screen is made from stainless steel (TWP Inc., CA) with a mesh size of $80 \mu \mathrm{m}$. This prevents fall-through of the $100 \mu \mathrm{m}$ diameter 


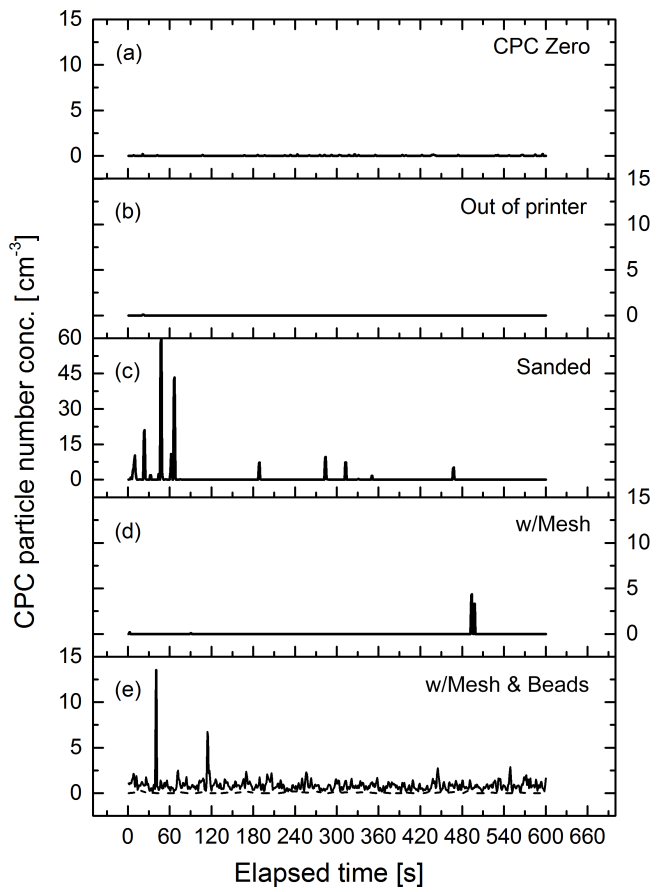

Figure 4. Time-series measurements of particle number concentrations: (a) CPC with filter; (b) freshly printed generator; (c) through the generator after wet sanding; (d) through the generator after wet sanding and installing the porous screen; (e) fully assembled generator including porous screen and bronze beads atop as bed material, without (solid line) and with a stainless steel insert (dashed line).

bronze beads that form the bed. Above the porous screen is a $35 \mathrm{~mm}$ long and $25.4 \mathrm{~mm}$ diameter elutriator tube; the bronze bead bed is located inside the elutriator. The elutriator tube is topped with a lid with a $6.35 \mathrm{~mm}(0.25 \mathrm{in}$.) outlet. We investigate configurations both with and without a stainless steel insert forming the walls of the elutriator. To prevent leakage, lids are equipped with inner side $\mathrm{O}$ rings. Based on the number of instruments connected to the generator, lids designed with single or multiple $6.35 \mathrm{~mm}$ outlets can be installed (a single outlet lid is shown in Fig. 2). Mounts for a rotameter and a $3 \mathrm{~mm}$ light-emitting diode (LED) to illuminate the bed were designed at the left side of the generator body. Mounting holes at the bottom were designed to secure the generator to a surface during operation. The overall dimensions of PRIZE are $70 \mathrm{~mm} \times 60 \mathrm{~mm} \times 98 \mathrm{~mm}$ (width, depth, height). All designed parts are saved as style files (.stl) to be readable by the $3-\mathrm{D}$ printer software.

\subsection{Manufacturing}

The generated construction files were uploaded to the 3D printer software (PreForm, Formlabs Inc.). In the program, the parts were oriented on the virtual build platform and scaffolding with $0.5 \mathrm{~mm}$ contact points were generated for support during the printing process. The oriented and

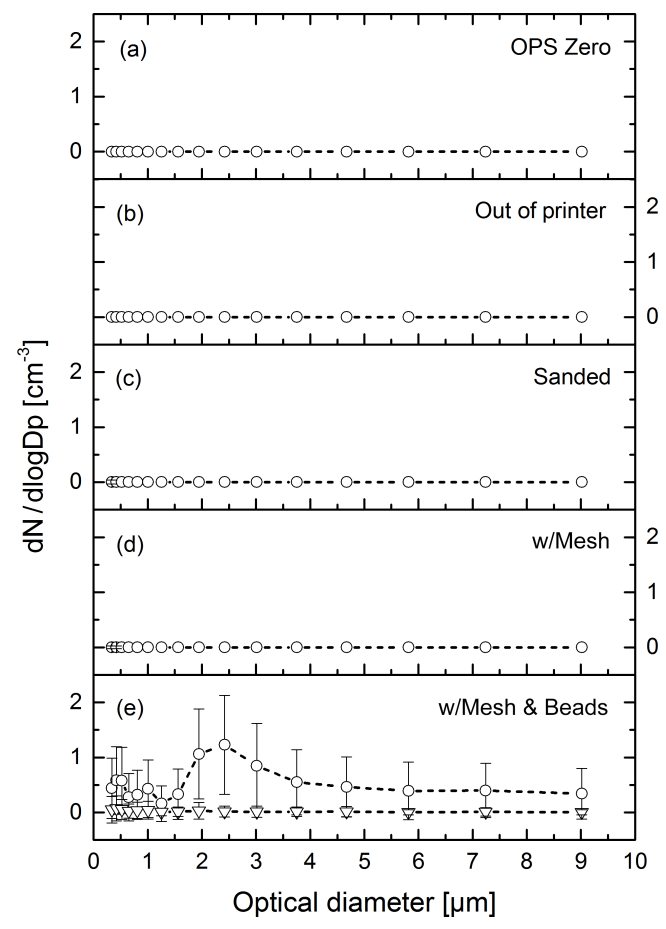

Figure 5. Average particle size distributions: (a) OPS with filter; (b) freshly printed generator; (c) through the generator after wet sanding; (d) through the generator after wet sanding and installing the porous screen; (e) fully assembled generator including porous screen and bronze beads atop as bed material, without (circles) and with a stainless steel insert (triangles).

supported parts were then positioned on the virtual build platform and uploaded to the 3-D stereolithography (SLA) printer (Form 2, Formlabs Inc.). Clear photopolymer resin (FLGPCL02, Formlabs Inc.) was used as the printing material. This allowed for observation of the particle generation. At the start of the print process the resin was automatically heated to $31{ }^{\circ} \mathrm{C}$ and kept at this temperature until the print was finished. The liquid resin is cured through photopolymerization by a $405 \mathrm{~nm}$ violet laser. The resolution of the printed layers can be adjusted to 25,50 or $100 \mu \mathrm{m}$. Using the highest resolution (of $25 \mu \mathrm{m}$ ), printing lasted $\sim 19 \mathrm{~h}$, while using the lowest resolution only $\sim 7 \mathrm{~h}$ were required. The PRIZE used in this study was printed with $100 \mu \mathrm{m}$ resolution with no significant performance changes observed across this resolution range.

The printed parts were removed from the build platform and agitated in isopropyl alcohol (IPA) for $\sim 20 \mathrm{~min}$ to remove uncured resin. Snips were used to remove the support structure from the printed parts. Residual supports marks were removed by wet sanding in a two-step process: an initial coarse sanding with grit size 800 and a second fine sanding with grit size 2000. To increase the strength of the printed parts, the manufacturer recommends a 60 min post-curing with a $405 \mathrm{~nm}$ light source (it should be noted this curing 

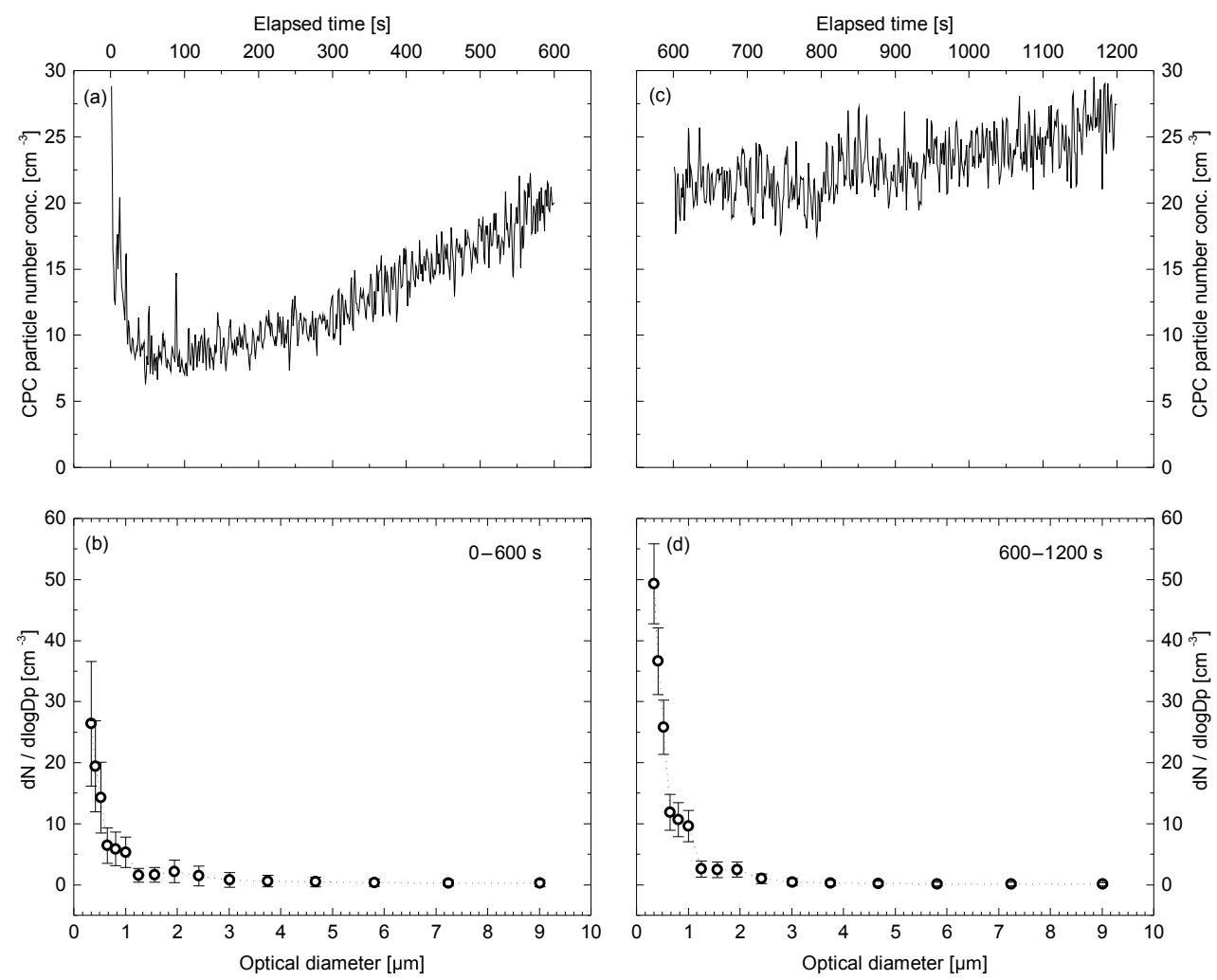

Figure 6. Arizona Test Dust measurements: (a) particle number concentration for the first $600 \mathrm{~s}$; (b) corresponding particle size distribution; (c) particle number concentration for the second $600 \mathrm{~s}$; (d) corresponding particle size distribution.

time also depends on the size and the wall thickness of the printed part). The printed generator parts were post-cured overnight $(\sim 8 \mathrm{~h})$ in a custom-built UV box. Inside are 300 surface-mount device (SMD) LED emitting at $405 \mathrm{~nm}$, with a total intensity of $934.8 \mathrm{~cd}$. After post-curing, the parts were polished using a Dremel with a soft felt bob.

\subsection{Experimental setup}

A schematic of the experimental setup with the relevant flow rates used in this study is shown in Fig. 3. Dry filtered nitrogen was used as the carrier gas. The flow was controlled by a rotameter (MR3A, Omega Engineering). Flow tests with only the $100 \mu \mathrm{m}$ bronze beads (ACuPowder International LLC) showed that $4.0 \mathrm{~L} \mathrm{~min}^{-1}$ was sufficient to create a "boiling" motion in the fluidized bed (i.e., the threshold where the gas did not only pass through the pore space of the beads without moving them), visible through the clear resin wall of the elutriator. All measurements in this study were therefore performed at $4.0 \mathrm{~L} \mathrm{~min}^{-1}$. At the outlet of the generator the flow was split into three pathways. The first was connected to a condensation particle counter to measure particle number concentrations in the size range from 0.007 to $2.0 \mu \mathrm{m}$ (CPC, BMI Inc.), the second to an optical particle sizer to determine particle number size distributions in the size range from 0.3 to $10 \mu \mathrm{m}$ (OPS model 3330, TSI Inc.) and the third to a filter open to lab for excess air.

\section{Results}

Three types of experiments were conducted to demonstrate the performance of PRIZE. First, control experiments at different assembly stages to verify minimal particle generation by the generator itself. Second, a mineral dust sample was added to the generator and a time-series measurement was performed. Third, a sensitivity study was performed on the effect of generated particle number concentration as function of mineral dust mass added to the generator. In addition, PRIZE was used to disperse an arid soil sample collected in Saudi Arabia. Data for each experiment and the soil dust dispersion are presented in the subsequent sections.

\subsection{Control experiments}

Before generator assembly, measurements with the CPC and OPS coupled to a filter (IDN-4G, Parker) were performed. No particles were detected, providing a zero background for the experiments (Figs. 4a, 5a). Connecting the generator to the CPC and OPS after printing also showed no particles, indicating that PRIZE was not generating particles at this 


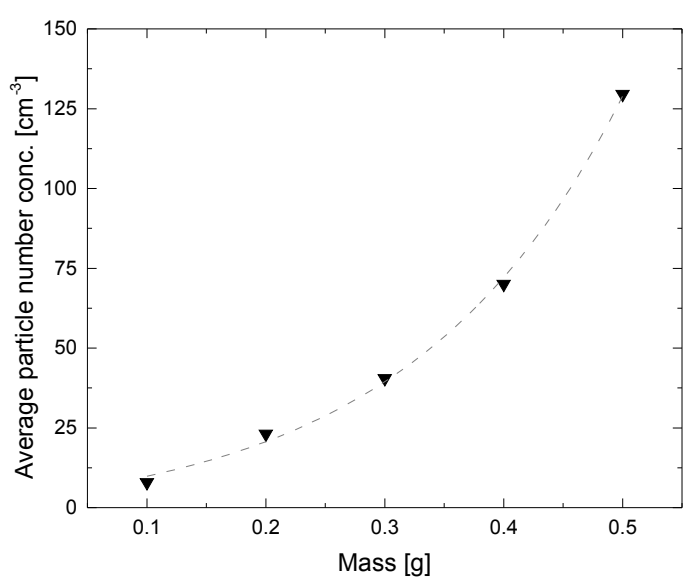

Figure 7. Particle number concentration generated as a function of Arizona Test Dust mass in the fluidized bed (triangles) with a fitted exponential curve (dashed line).

stage (Figs. 4b, 5b). Particles were observed by the CPC postsanding and are likely residuals of the sanding process; we suggest a thorough cleaning (e.g. via immersion sonication) to eliminate these, although they were observed to asymptote to zero after $450 \mathrm{~s}$ (Figs. 4c, 5c). Because no particles were observed in the OPS, we assume their diameter was smaller than $0.3 \mu \mathrm{m}$ (i.e., below the detection limit of the OPS). Installing the porous screen did not cause significant particle generation. Introduction of the bronze beads resulted in an OPS maximum particle concentration of $\sim 1.5 \mathrm{~cm}^{-3}$ with a mode at $\sim 2.5 \mu \mathrm{m}$ in diameter; a similar particle concentration was detected at the CPC. The particle concentration at this stage could be reduced to $\sim 0.1 \mathrm{~cm}^{-3}$ with insertion of a stainless steel tube into the elutriator (Figs. 4e, 5e). This prevented direct contact of the bronze beads with the generator wall and indicates that some abrasion of the printed surface can take place.

\subsection{Mineral dust experiments}

Arizona Test Dust (ATD; Powder Technology Inc., MN, USA) was used as the sample material in this study. The nominal size of particles ranged from 0 to $3 \mu \mathrm{m}$ and $0.2 \mathrm{~g}$ ATD were initially added to the generator. A measurement time of $1200 \mathrm{~s}$ was split into two $600 \mathrm{~s}$ segments to determine the particle concentration as a function of time. The first $600 \mathrm{~s}$ showed a decrease after startup, a brief drop in concentration and then an upward asymptote to $\sim 25 \mathrm{~cm}^{-3}$ at the CPC (Fig. 6a). The size distribution in the OPS remained more or less constant with a final maximum particle concentration of $\sim 25 \mathrm{~cm}^{-3}$ centered at $0.3 \mu \mathrm{m}$ diameter (Fig. 6b). Although this is the lowest size bin of the OPS, the similarity in CPC and OPS concentrations indicate most generated particles fall within, and towards the low end of, the OPS size range. The second $600 \mathrm{~s}$ showed a stable particle concentration from 25 to $30 \mathrm{~cm}^{-3}$ in the CPC (Fig. 6c). The shape

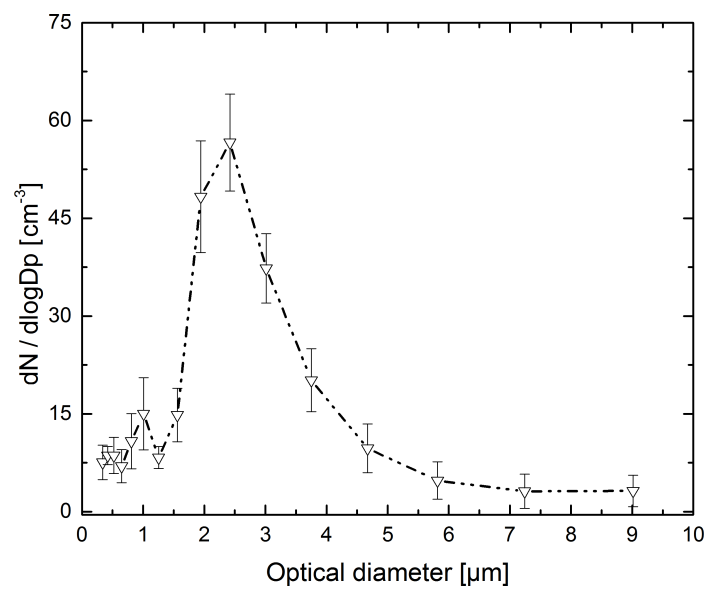

Figure 8. Average particle size distribution with corresponding standard deviations as a function of optical particle diameter. Particles were generated from a Saudi Arabian arid soil dust sample.

of the size distribution did not change over time, showing the maximum particle concentration remained at $\sim 0.3 \mu \mathrm{m}$ (Fig. 6d).

A sensitivity study of the number concentration of generated particles as a function of ATD mass added to the generator was also performed. ATD was added stepwise from 0.1 to $0.5 \mathrm{~g}$ to the clean PRIZE with measurements made after an initial $600 \mathrm{~s}$ "warm-up" period, the stabilization time indicated in the initial experiment. This procedure was repeated at each mass loading. The resulting particle number concentrations showed an exponential growth with increasing mass load in the fluidized bed from 10 to $150 \mathrm{~cm}^{-3}$ (Fig. 7). A curve fitted to the data provides a particle number concentration (PNC) as a function of the mass load (ML) for this ATD sample:

$\mathrm{PNC}=8.414 \cdot \exp \left(\frac{\mathrm{ML}}{0.18081}\right)-4.75126$.

Eq. (1) can be used to estimate the generated particle number concentration. For a sample mass of $0.75 \mathrm{~g}, \sim 525 \mathrm{~cm}^{-3}$; $1 \mathrm{~g} \sim 2120 \mathrm{~cm}^{-3}$ will ideally be generated. The exponential form of Eq. (1) should not be used to multi-gram quantities; it is used here to demonstrate that particle size selection instruments, e.g. a differential mobility analyzer (DMA), could be used in combination with PRIZE and higher mass loadings. While the purpose of this work is to demonstrate the applicability of PRIZE for the aerosolization of small sample sizes, some researchers may use it for dispersion followed by separation. Assuming $\sim 10 \%$ of the introduced particles are selected as monodisperse aerosol particles, output concentrations of $\sim 15-210 \mathrm{~cm}^{-3}$ are achievable. The final output concentration of monodisperse particles will depend on several factors, including the sample material mode size, the particle size selected, the shape factor, etc. (Wiedensohler et al., 2012). 
A final experiment was conducted to demonstrate the use of PRIZE for dispersion of collected soil dust samples. Figure 8 provides a size distribution of particles dispersed from an arid soil sample collected in Dhahrat Laban (west of Riyadh, Saudi Arabia).

\section{Conclusions}

This study describes the design, manufacture and proof-ofconcept experiments of the 3-D printed fluidized bed generator PRIZE, which is a compact, simple and low-cost addition to existing dry particle generation instruments. The generator is capable of dispersing aerosol particles from dry material without itself generating significant particles $(<5 \%$ by number at $0.2 \mathrm{~g}$ of ATD without a stainless steel insert and negligible with an insert). Using SLA technology makes this a low-cost instrument when compared to commercially available FBGs. Furthermore, the generator is compact and easy to set up as it requires only particle-free pressurized gas and gram-quantity samples. It is therefore ideal for use in minimally appointed laboratory and field conditions.
We demonstrate the use of PRIZE for collected samples of soil dust and note its use with mass spectrometry or transmission electron microscopy. Due to the preservation of the original chemical composition of the aerosolized particles, which is a major advantage of dry particle generation, investigations of cloud condensation and ice nucleation potential can be made without aqueous processing artifacts. Furthermore, we demonstrate with calculations that mass loadings larger than $0.5 \mathrm{~g}$ could be used in combination with differential mobility separation for production of size-selected aerosols.

Data availability. The .stl files for PRIZE are available up on request. 


\section{Appendix A}

Table A1. PRIZE assembly stages, the action taken and the particle detection results at the CPC and OPS. Corresponding particle number concentration time-series measurements and size distributions are provided in Figs. 4 and 5, respectively.

\begin{tabular}{llll}
\hline Stage & Action & CPC & OPS \\
\hline Out of printer & Freshly printed test & No (4b) & No (5b) \\
Sanded & Wet sanded with 800 and 2000 grit & Yes (4c) & No (5c) \\
With mesh & Screen installed & Yes (4d) & No (5d) \\
With mesh and beads & Bed material added & Yes (4e) & Yes (5e) \\
\hline
\end{tabular}


Competing interests. The authors declare that they have no conflict of interest.

Acknowledgements. We acknowledge funding from the Center for Complex Engineering Systems at the King Abdulaziz City for Science and Technology, NSF (AGS-1461347), DOE (DESC0014487) and NASA (NNX13AO15G).

Edited by: F. Pope

Reviewed by: two anonymous referees

\section{References}

Ardon-Dryer, K. and Levin, Z.: Ground-based measurements of immersion freezing in the eastern Mediterranean, Atmos. Chem. Phys., 14, 5217-5231, https://doi.org/10.5194/acp-145217-2014, 2014.

Boucher, O., Randall, D., Artaxo, P., Bretherton, C., Feingold, G., Forster, P., Kerminen, V.-M., Kondo, Y., Liao, H., Lohmann, U., Rasch, P., Satheesh, S., Sherwood, S., Stevens, B., and Zhang, X.: Clouds and Aerosols, in: Climate Change 2013: The Physical Science Basis. Contribution of Working Group I to the Fifth Assessment Report of the Intergovernmental Panel on Climate Change, chapter 7, Cambridge University Press, Cambridge, UK and New York, NY, USA, 2013.

Boucher, R. F. and Lua, A. C.: A stable, high-concentration, dry aerosol generator, J. Aerosol Sci., 13, 499-511, 1982.

Clemente, A., Balas, F., Pilar Lobera, M., Irusta, S., and Santamaria, J.: Fluidized Bed Generation of Stable Silica Nanoparticle Aerosols, Aerosol Sci. Tech., 47, 867-874, 2013.

Cziczo, D. J., Garimella, S., Raddatz, M., Hoehler, K., Schnaiter, M., Saathoff, H., Moehler, O., Abbatt, J. P. D., and Ladino, L. A.: Ice nucleation by surrogates of Martian mineral dust: What can we learn about Mars without leaving Earth?, J. Geophys. Res.Planet., 118, 1945-1954, 2013.

Forsyth, B., Liu, B. Y. H., and Romay, F. J.: Particle charge distribution measurement for commonly generated laboratory aerosols, Aerosol Sci. Tech., 28, 489-501, 1998.

Garimella, S., Huang, Y.-W., Seewald, J. S., and Cziczo, D. J.: Cloud condensation nucleus activity comparison of dryand wet-generated mineral dust aerosol: the significance of soluble material, Atmos. Chem. Phys., 14, 6003-6019, https://doi.org/10.5194/acp-14-6003-2014, 2014.

Gauthier, D., Zerguerras, S., and Flamant, G.: Influence of the particle size distribution of powders on the velocities of minimum and complete fluidization, Chem. Eng. J., 74, 181-196, 1999.

Geldart, D.: Types of gas fluidization, Powder Technol., 7, 285-292, 1973.

Guichard, J. C.: Aerosol Generation Using Fluidized Beds, in: Fine Particles: Aerosol Generation, Measurement, Sampling, and Analysis, edited by: Liu, B., Academic Press, New York, 1976.

Hartmann, S., Wex, H., Clauss, T., Augustin-Bauditz, S., Niedermeier, D., Roesch, M., and Stratmann, F.: Immersion Freezing of Kaolinite: Scaling with Particle Surface Area, J. Atmos. Sci., 73, 263-278, https://doi.org/10.1175/JAS-D-15-0057.1, 2016.
Hesse, E., Ulanowski, Z., and Kaye, P. H.: Stability characteristics of cylindrical fibres in an electrodynamic balance designed for single particle investigation, J. Aerosol Sci., 33, 149-163, 2002.

Hinds, W. C.: Aerosol Technology: Properties, Behavior, and Measurement of Airborne Particles, 2nd Edn., Wiley Interscience, New York, 1999.

Hiranuma, N., Moehler, O., Yamashita, K., Tajiri, T., Saito, A., Kiselev, A., Hoffmann, N., Hoose, C., Jantsch, E., Koop, T., and Murakami, M.: Ice nucleation by cellulose and its potential contribution to ice formation in clouds, Nat. Geosci., 8, 273-277, 2015.

Kumar, P., Sokolik, I. N., and Nenes, A.: Cloud condensation nuclei activity and droplet activation kinetics of wet processed regional dust samples and minerals, Atmos. Chem. Phys., 11, 8661-8676, https://doi.org/10.5194/acp-11-8661-2011, 2011.

Lind, T., Danner, S., and Guentay, S.: Monodisperse fine aerosol generation using fluidized bed, Powder Technol., 199, 232-237, 2010.

Marple, V. A., Liu, B. Y. H., and Rubow, K. L.: A dust generator for laboratory use, Am. Ind. Hyg. Assoc. J., 39, 26-32, 1978.

Mehrani, P., Bi, H. T., and Grace, J. R.: Bench-scale tests to determine mechanisms of charge generation due to particle-particle and particle-wall contact in binary systems of fine and coarse particles, Powder Technol., 173, 73-81, 2007.

Moreno, F. and Blann, D.: Large Flow Rate Redispersion Aerosol Generator, in: Fine Particles: Aerosol Generation, Measurement, Sampling, and Analysis, edited by: Liu, B., Academic Press, New York, 1976.

Murphy, D. M.: The design of single particle laser mass spectrometers, Mass. Spectrom. Rev., 26, 150-165, 2006.

Niedermeier, D., Hartmann, S., Shaw, R. A., Covert, D., Mentel, T. F., Schneider, J., Poulain, L., Reitz, P., Spindler, C., Clauss, T., Kiselev, A., Hallbauer, E., Wex, H., Mildenberger, K., and Stratmann, F.: Heterogeneous freezing of droplets with immersed mineral dust particles - measurements and parameterization, Atmos. Chem. Phys., 10, 3601-3614, https://doi.org/10.5194/acp10-3601-2010, 2010.

Sullivan, R. C., Moore, M. J. K., Petters, M. D., Kreidenweis, S. M., Roberts, G. C., and Prather, K. A.: Timescale for hygroscopic conversion of calcite mineral particles through heterogeneous reaction with nitric acid, Phys. Chem. Chem. Phys., 11, 7826-7837, 2009.

Sullivan, R. C., Moore, M. J. K., Petters, M. D., Kreidenweis, S. M., Qafoku, O., Laskin, A., Roberts, G. C., and Prather, K. A.: Impact of Particle Generation Method on the Apparent Hygroscopicity of Insoluble Mineral Particles, Aerosol Sci. Tech., 44, 830-846, 2010.

Tang, M. J., Cziczo, D. J., and Grassian, V. H.: Interactions of Water with Mineral Dust Aerosol: Water Adsorption, Hygroscopicity, Cloud Condensation and Ice Nucleation, Chem. Rev., 116, 42054259, 2016.

Tobo, Y., DeMott, P. J., Raddatz, M., Niedermeier, D., Hartmann, S., Kreidenweis, S. M., Stratmann, F., and Wex, H.: Impacts of chemical reactivity on ice nucleation of kaolinite particles: A case study of levoglucosan and sulfuric acid, Geophys. Res. Lett., 39, L19803, https://doi.org/10.1029/2012GL053007, 2012.

Wang, Z., Kwauk, M., and Li, H.: Fluidization of fine particles, Chem. Eng. Sci., 53, 377-395, 1998. 
Wiedensohler, A., Birmili, W., Nowak, A., Sonntag, A., Weinhold, K., Merkel, M., Wehner, B., Tuch, T., Pfeifer, S., Fiebig, M., Fjäraa, A. M., Asmi, E., Sellegri, K., Depuy, R., Venzac, H., Villani, P., Laj, P., Aalto, P., Ogren, J. A., Swietlicki, E., Williams, P., Roldin, P., Quincey, P., Hüglin, C., Fierz-Schmidhauser, R., Gysel, M., Weingartner, E., Riccobono, F., Santos, S., Grüning, C., Faloon, K., Beddows, D., Harrison, R., Monahan, C., Jennings, S. G., O’Dowd, C. D., Marinoni, A., Horn, H.-G., Keck, L., Jiang, J., Scheckman, J., McMurry, P. H., Deng, Z., Zhao, C. S., Moerman, M., Henzing, B., de Leeuw, G., Löschau, G., and Bastian, S.: Mobility particle size spectrometers: harmonization of technical standards and data structure to facilitate high quality long-term observations of atmospheric particle number size distributions, Atmos. Meas. Tech., 5, 657-685, https://doi.org/10.5194/amt-5-657-2012, 2012. 